\title{
Overexpression of MTH1 and OGG1 proteins in ulcerative colitis-associated carcinogenesis
}

\author{
YOSHITERU KUMAGAE ${ }^{1}$, MINAKO HIRAHASHI ${ }^{1}$, KATSUMI TAKIZAWA $^{1}$, \\ HIDETAKA YAMAMOTO ${ }^{1}$, MASAKI GUSHIMA ${ }^{2}$, MOTOHIRO ESAKI ${ }^{3}$, TAKAYUKI MATSUMOTO ${ }^{4}$, \\ MASAFUMI NAKAMURA ${ }^{3}$, TAKANARI KITAZONO ${ }^{3}$ and YOSHINAO ODA ${ }^{1}$
}

\begin{abstract}
${ }^{1}$ Department of Anatomic Pathology, Graduate School of Medical Sciences, Kyushu University, Fukuoka, Fukuoka 812-8582;
${ }^{2}$ Department of Medical Gastroenterology, Shimonoseki Hospital, Yamaguchi, Yamaguchi 750-8520; ${ }^{3}$ Department of Medicine and Clinical Science, Surgery and Oncology, Graduate School of Medical Sciences, Kyushu University, Fukuoka, Fukuoka 812-8582; ${ }^{4}$ Division of Gastroenterology, Department of Internal Medicine, School of Medicine, Iwate Medical University, Morioka, Iwate 020-8505, Japan
\end{abstract}

Received December 8, 2016; Accepted September 5, 2017

DOI: $10.3892 / \mathrm{ol} .2018 .8812$

\begin{abstract}
Oxidative stress, demonstrated by an accumulation of 8-hydroxy-2'-deoxyguanosine (8-OHdG), results in DNA damage, which is normally repaired by base excision repair enzymes including 8-OHdG DNA glycosylase (OGG1) and human MutY homolog (MUTYH), in addition to nucleotide pool sanitizing enzymes including MutT Homolog 1 (MTH1). Abnormalities of this repair system are present in various cancer types. The present study aimed to elucidate the clinicopathological significance of altered expression levels of inducible nitric oxide synthase (iNOS), 8-OHdG, OGG1, MTH1 and MUTYH in ulcerative colitis (UC) and UC-associated neoplasms. Immunohistochemical staining for these markers and p53 in 23 cases of UC-associated neoplasm (Group A, 14 carcinomas and nine dysplasias), 16 cases of UC without neoplasm (Group B) and 17 cases of normal colon specimens (Group C) was performed. Mutation analyses was conducted for KRAS proto-oncogene, GTPase ( $K$-ras), tumor protein P53 (TP53) and isocitrate dehydrogenase (NADP (+)) 1, cytosolic (IDHI) genes. Immunohistochemically, the iNOS, 8-OHdG, OGG1 and MTH1 expression levels were increased in Groups A and B compared with Group C. The OGG1 and MTH1 expression levels in Group A were also increased compared with Group B. Group A and Group B exhibited increased cytoplasmic expression and decreased nuclear expression of MUTYH compared with Group C. Mutations of $K$-ras and
\end{abstract}

Correspondence to: Professor Yoshinao Oda, Department of Anatomic Pathology, Graduate School of Medical Sciences, Kyushu University, Maidashi 3-1-1, Higashi-ku, Fukuoka, Fukuoka 812-8582, Japan

E-mail: oda@surgpath.med.kyushu-u.ac.jp

Key words: ulcerative colitis, carcinoma, oxidative stress, OGG1, MTH1, base excision repair enzyme
TP53 were detected in 2/21 (9.5\%) and 10/22 (45.5\%) cases of Group A, respectively. IDHI mutation was not detected in any cases. These findings suggest that, as a response to oxidative damage, OGG1 and MTH1 may be upregulated in UC through an inflammatory condition that progresses to cancer formation. Persisting oxidative damage stress may play a role in the pathogenesis of UC-associated tumors.

\section{Introduction}

Ulcerative colitis (UC) is an inflammatory bowel disease characterized by periods of inflammatory recurrence and remission events, accompanied by cell death and regeneration of the colonic mucosa. Patients with UC face an increased risk of UC-associated neoplasm (UCAN) including dysplasia and carcinoma (1). The incidence of colorectal dysplasia in UC patients was observed to be $1.9 \%$ at 5 years, $5.1 \%$ at 15 years, and $9.2 \%$ at 25 years after the onset of the UC (2). The elevated risk of UCAN development is associated with several factors such as disease duration, the extent and severity of inflammation, family history of colorectal carcinoma, backwash ileitis, and primary sclerosing cholangitis (3-5).

The pathogenesis of UCAN is thought to be associated with oxidative DNA damage (6). Nitric oxide (NO) is synthesized by nitric oxide synthase (iNOS) and contributes to the pathogenesis of various types of cancer including colonic carcinoma (7-9). It is known that 8-oxoguanine (8-oxoG) is the most stable product of the base damage due to oxidative stress, and 8-oxoG mismatches with adenine residues, leading to a G:C to T:A transversion mutation $(10,11)$. 8-oxoG and 8-hydroxy-2'-deoxyguanosine (8-OHdG) undergo keto-enol tautomerism, which favors the oxidized product 8-oxodG (12). It was reported that the levels of 8 -OHdG are elevated in colorectal cancer and UC-associated dysplasia $(6,13)$.

DNA damage is normally repaired by base excision repair (BER) enzymes such as 8-OHdG DNA glycosylase (OGG1) and human MutY homolog (MUTYH) and nucleotide pool sanitizing enzyme such as MutT Homolog 1 (MTH1). MTH1 
protein exists in the nucleotide pool and functions to prevent the misincorporation of $8-\mathrm{OHdG}$ by hydrolyzing $8-\mathrm{OH}-\mathrm{dGTP}$ to 8-OH-dGMP (14). OGG1 excises 8-OHdG, which has been mispaired with cytosine. MUTYH excises adenines that have been misincorporated opposite $8-\mathrm{OH}-\mathrm{G}$ during replication (15). Altered expressions of OGG1, MTH1 and MUTYH have been reported in various types of cancer (14,16-19). In our previous study, we showed that the nuclear expression of MUTYH was lower in UCAN and UC than in the non-inflamed mucosa (18). However, the expression status of OGG1 and MTH1 in UCAN has not been reported to date.

Various types of genetic mutation have been reported in UCAN, including $K$-ras (30\%), TP53 (40-80\%), pl6 (100\%), CTNNB1 (45-50\%) and APC (10-30\%) (20,21). Isocitrate dehydrogenase 1 (IDH1) catalyzes the oxidative carboxylation of isocitrate to $\alpha$-ketoglutarate, resulting in the production of nicotinamide adenine dinucleotide phosphate. Mutations of IDHI gene lead to an accumulation of 2-hydroxyglutarate that can induce the hypermethylation of DNA $\mathrm{CpG}$ islands, resulting in altered gene transcription and genome stability $(22,23)$. A 2014 study showed that adenocarcinomas associated with inflammatory bowel disease had IDHI mutations more frequently compared to sporadic colon cancer (23).

Here we attempted to elucidate the mechanisms of DNA damage and repair in UCAN by evaluating the accumulation of oxidative stress markers and expression DNA repair proteins, iNOS, 8-OHdG, OGG1, MTH1 and MUTYH in UC and UC-associated neoplasms. We also examined the frequencies of K-ras, TP53 and IDHI gene mutations as candidates of oxidative stress-induced DNA damage.

\section{Materials and methods}

Cases and histological evaluation. We examined the surgical specimens of 23 cases of UC-associated neoplasia (Group Athe) including 14 carcinoma cases (Group A1) and nine dysplasia cases (Group A2), 16 cases of UC patients without neoplasia (Group B) and 17 cases of normal colon (Group C). These lesions were surgically resected at Kyushu University Hospital and its referral hospitals during the 28-year period from 1987 to 2015. The diagnosis of UC had been made based on clinical, endoscopic and histologic findings. All neoplastic lesions were classified according to the criteria proposed by Riddell et al (24). Patients in Group B were in the active phase pf ulcerative colitis and underwent surgery because of fulminant or intractable disease. Group B specimens showed diffuse and severe neutrophilic infiltration, goblet cell depletion, cryptitis, and crypt abscess indicating the active phase of UC. As for Group C, we obtained the specimens of non-cancerous tissue at least $10 \mathrm{~cm}$ apart from sporadic colorectal cancer lesions of non-UC patients. Group C specimens showed only slight to mild inflammatory infiltrate.

The study was approved by the Institutional Review Boards of Kyushu University Hospital (no. 27-388).

Immunohistochemical analysis. Formalin-fixed and paraffin-embedded tissue specimens were used for immunohistochemical stainings for iNOS, 8-OHdG, OGG1, MTH1, MUTYH and p53. The primary antibodies and immunohistochemical staining procedures are summarized in Table I. In brief, after the pretreatment, the primary antibody was applied to the specimen and left overnight at $4^{\circ} \mathrm{C}$. Sections were then incubated with a biotinylated secondary antibody for $20 \mathrm{~min}$, followed by the use of a streptavidin-biotin-alkaline phosphatase kit (Nichirei, Tokyo) for $8-\mathrm{OHdG}$. The reaction was visualized with substrate for alkaline phosphatase for $8-\mathrm{OHdG}$. For other markers, Envision+ (Dako, Glostrup, Denmark) was used as the secondary antibody, and 3,3-diamino-benzidine was used for visualization. Finally, sections were counterstained with Mayer's hematoxylin.

For the evaluation of immunohistochemical staining, we counted a minimum of 500 cells on each slide. $8-\mathrm{OHdG}$ immunoreactivity in the colorectal crypts was evaluated by the labeling index (LI) of nuclear staining (18). We divided the sections into High and Low expression groups using the median as a reference value, and we compared these values with other immunohistochemical scores and the percentage of gene mutation. The expressions of iNOS expression were evaluated as described (25). The expression level was graded based on the combination of the proportion and the intensity of immunoreactive cells. Proportion scores (PS) were rated on the following scale: 0 (no staining) $1(<1 \%), 2$ (1\% to $<10 \%), 3(10 \%$ to <33\%), $4(33-66 \%)$ and 5 (>66\%). Intensity scores (IS) were rated on the scale 0 (no staining), 1 (weak), 2 (moderate) and 3 (strong). The total score was obtained by adding the PS and the IS.

The MUTYH expression was evaluated as described (18). The proportion of nuclear staining of the colorectal crypts was classified using a three-grade scale: 0 (no staining), 1 (5-50\%) and $2(>50 \%)$, and the intensity of cytoplasmic expression was classified with a two-grade scale (1, weak; 2 , strong).

The expressions of MTH1 and OGG1 expression were evaluated as described (16). Staining intensity was rated on the following scale: 0 (no staining), 1 (weak), 2 (moderate) and 3 (strong). The proportion of immunoreactive cells was then scored as 0 (no staining), 1 (1-50\%) or 2 (51-100\%). The final score was calculated by multiplying the IS by the PS, achieving theoretical results ranging from 0 to 6 . Immunoreactivity for p53 was regarded as positive when $>10 \%$ of the cells were stained $(26,27)$.

Mutational analysis of K-ras, TP53 and IDH1. For the mutational analysis, we analyzed the cases of 23 patients with UCAN. Genomic DNA was extracted from paraffin-embedded sections using a macrodissection or microdissection technique. For the macrodissection technique, histological areas measuring approx. $\geq 1 \mathrm{~cm}$ in dia. were removed by macroscopic dissection with a needle so as to contain $>70 \%$ tumor cells. For the microdissection technique, the tumor cells were isolated selectively using laser microdissection (AS LMD system; Leica, Nussloch, Germany) and a pressure catapulting system to get at least 1,000 tumor cells per sample for a polymerase chain reaction (PCR) analysis. Subsequently, genomic DNA was extracted from the samples using a QIAamp ${ }^{\circledR}$ DNA Micro kit (Qiagen, Tokyo) and DNeasy Blood \& Tissue kits (Qiagen), respectively, in accordance with the manufacturer's protocols.

The mutational analysis for $K$-ras, TP53 and IDHI was performed using PCR and direct sequencing. Mutational hot spots of K-ras (codon12 and 13), TP53 (exons 5-9) and IDHI (R132) were included in these PCR analyses $(22,28,29)$. 
Table I. Antibodies used in immunohistochemical stain.

\begin{tabular}{|c|c|c|c|c|c|}
\hline Antigen & Primary antibodies & & Dilution & Source & Antigen retrieval \\
\hline iNOS & nos typeII & Mouse monoclonal & $1: 100$ & $\begin{array}{l}\text { BD Biosciences, } \\
\text { Franklin Lakes, NJ }\end{array}$ & $\begin{array}{l}\text { Microwaved for } 30 \text { min in } \\
\text { target retrieval solution high } \mathrm{pH} \\
\text { (DAKO, Glostrup, Denmark) }\end{array}$ \\
\hline 8-OHdG & N45.1 & Mouse monoclonal & $1: 20$ & $\begin{array}{l}\text { Japanese aging } \\
\text { control institute, } \\
\text { Shizuoka, Japan }\end{array}$ & $\begin{array}{l}\text { Proteinase } \mathrm{K} \text { for } 7 \mathrm{~min} \text { incubate } \\
\text { with } 4 \mathrm{~N} \mathrm{HCl} \text { for } 20 \mathrm{~min} \text { and } \\
\text { with } 50 \mathrm{mM} \text { Tris base for } 5 \mathrm{~min}\end{array}$ \\
\hline OGG1 & NB100-106 & Rabbit polyclonal & $1: 250$ & $\begin{array}{l}\text { Novus Biologicals, } \\
\text { Littleton, } \mathrm{CO} \text {, }\end{array}$ & $\begin{array}{l}\text { Microwaved for } 30 \mathrm{~min} \text { in target } \\
\text { retrieval solution high } \mathrm{pH} \\
\text { (DAKO, Glostrup, Denmark) }\end{array}$ \\
\hline MTH1 & D-2 & Rabbit polyclonal & $1: 400$ & $\begin{array}{l}\text { Abcam, Cambridge, } \\
\text { England }\end{array}$ & $\begin{array}{l}\text { Microwaved for } 30 \mathrm{~min} \text { in target } \\
\text { retrieval solution high } \mathrm{pH} \\
\text { (DAKO, Glostrup, Denmark) }\end{array}$ \\
\hline MUTYH & ab13698 & Rabbit-polyclonal & $1: 50$ & $\begin{array}{l}\text { Abcam, Cambridge, } \\
\text { England }\end{array}$ & $\begin{array}{l}\text { Microwaved for } 30 \mathrm{~min} \text { in target } \\
\text { retrieval solution high } \mathrm{pH} \\
\text { (DAKO, Glostrup, Denmark) }\end{array}$ \\
\hline $\begin{array}{l}\text { p53 } \\
\text { citrate }\end{array}$ & PAb1801 & Mouse monoclonal & $1: 100$ & $\begin{array}{l}\text { Oncogene Research } \\
\text { Products, San Diego, } \\
\text { CA. }\end{array}$ & $\begin{array}{l}\text { Microwaved for } 10 \mathrm{~min} \text { in } \\
\text { buffer }(\mathrm{pH} 6.0)\end{array}$ \\
\hline
\end{tabular}

PCR reactions were performed in a thermocycler (Tgradient; Biometra, Gottingen, Germany). The amplified PCR products were then purified using Montage centrifugal filters (Millipore, Bedford, MA, USA). After purification, direct sequencing was performed using an ABI 3500 genetic analyzer (Applied Biosystems, Foster City, CA).

Statistical analysis. We examined the correlations among clinicopathological factors and molecular data using the Mann-Whitney U-test and Fisher's exact test. A P-value $<0.05$ was considered significant. As the post-hoc test, we re-examined the data using Tukey's test.

\section{Results}

Clinicopathological findings. The clinicopathological features of the patients are summarized in Table II. Among the 23 patients of the Group A (UC-associated neoplasm), 13 patients were men and 10 were women, with the median age of 48 years (range 25-77 years). The median disease duration of Group A was 16 years (range 0.5-35 years). The neoplastic lesions in both Group A1 (UC-associated carcinomas) and Group A2 (UC-associated dysplasia) were predominantly located in the left side of the colon and rectum.

Histologically, Group A2 lesions showed atypical columnar cells with hyperchromitic nuclei and mild nuclear stratification as low-grade dysplasia (LGD) (Fig. 1A), and prominent dystrophic goblet cells and/or severely atypical columnar cells with prominent nuclear stratification without vesicular nuclei, as high-grade dysplasia (HGD). Most of the carcinomas of Group A1 were well to moderately differentiated adenocarcinoma (Fig. 1B). Among the 16 patients of Group B (UC without neoplasm), nine patients were men and seven were women, with the median age of 43 years (range 22-77 years). The median disease duration of Group B was 6 years (range 0.5-31 years). The disease duration of UC was significantly longer in Group A compared to Group B $(\mathrm{P}=0.0067)$.

\section{Immunohistochemical analyses}

iNOS. The iNOS expression scores in Group A (median: 8) and Group B (median: 7) were significantly higher than that of Group $\mathrm{C}$ (median: 5) $(\mathrm{P}=0.0002, \mathrm{P}=0.0034$, respectively) (Table III, Figs. 1C and 2A). There was no significant difference in iNOS expression between Group A and Group B, or between Group A1UC+carc and Group A2 (Tables III and IV).

8-OHdG. The labeling indices of 8-OHdG in Group A (median: 49.3) and Group B (median: 53.6) were significantly higher than that in Group $\mathrm{C}$ (median: 29.1) $(\mathrm{P}=0.0002, \mathrm{P}=0.0034$, respectively) (Table III; Figs. 1D and 2B). There was no significant difference between Group A and Group B, or between Group A1 and Group A2 (Tables III and IV).

We then examined the correlation between the expression of 8-OHdG and other markers. The OGG1 scores of the high 8-OHdG cases (score 2: one case, score 4: five cases, score 6: five cases) and those of the low 8-OHdG cases (score 2: one case, score 4: five cases, score 6: five cases) revealed no significant correlations. The MTH1 scores of the high $8-\mathrm{OHdG}$ cases (score 2: no cases, score 4: six cases, score 6: five cases) and those of the low 8-OHdG cases (score 2: one case, score 4: four cases, score 6: six cases) revealed no significant correlations. No significant correlations with other markers were revealed (Table V).

OGG1. OGG1 expression was observed only in cytoplasmic regions in our cases, and both the intensity and the proportion of 


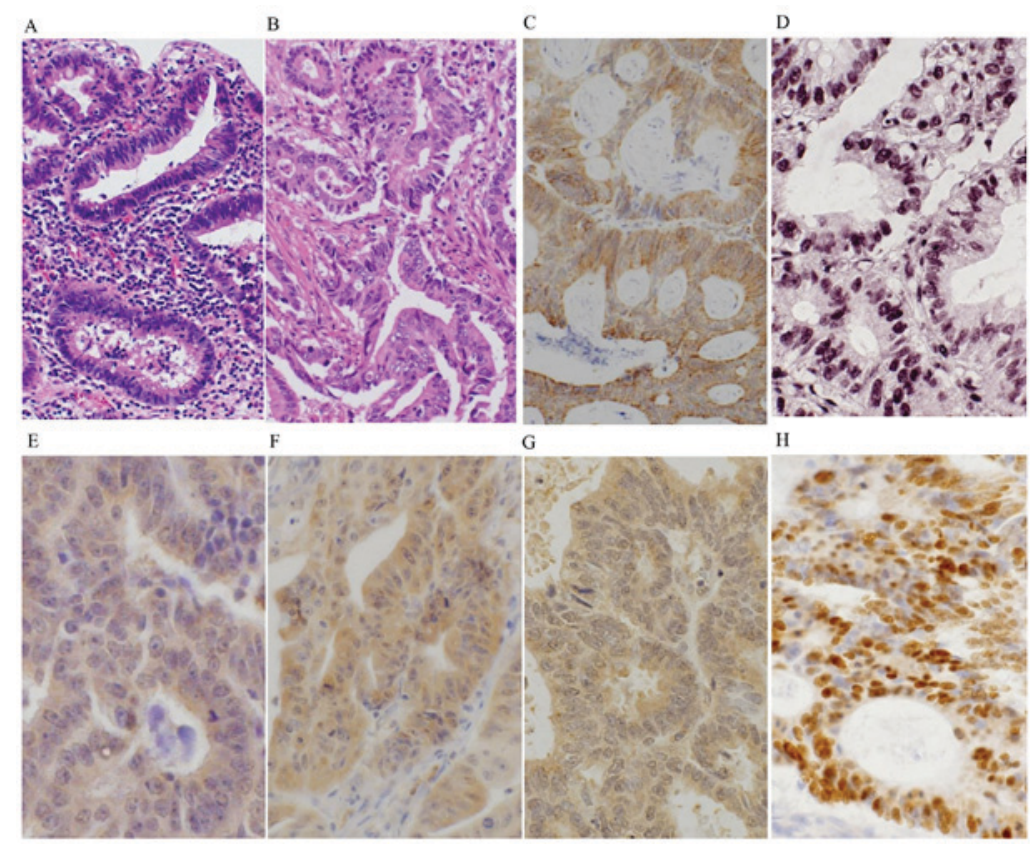

Figure 1. Representative images of (A and B) histology and (C-H) immunohistochemical stainings in the UC-associated neoplasms. (A) The UC-associated low-grade dysplasias (Group A2) were composed of atypical columnar cells with hyperchromatic nuclei and mild nuclear stratification. (B) The UC-associated carcinomas (Group A1) showed well to moderately differentiated adenocarcinoma, invading the stroma. Group A1 lesions showed diffuse and strong cytoplasmic expressions of (C) iNOS, (E) OGG1 and (F) MTH1, and nuclear accumulations of (D) 8-OHdG and (H) p53. (G) Group A1 lesions also exhibited high cytoplasmic staining and low nuclear staining for MUTYH.
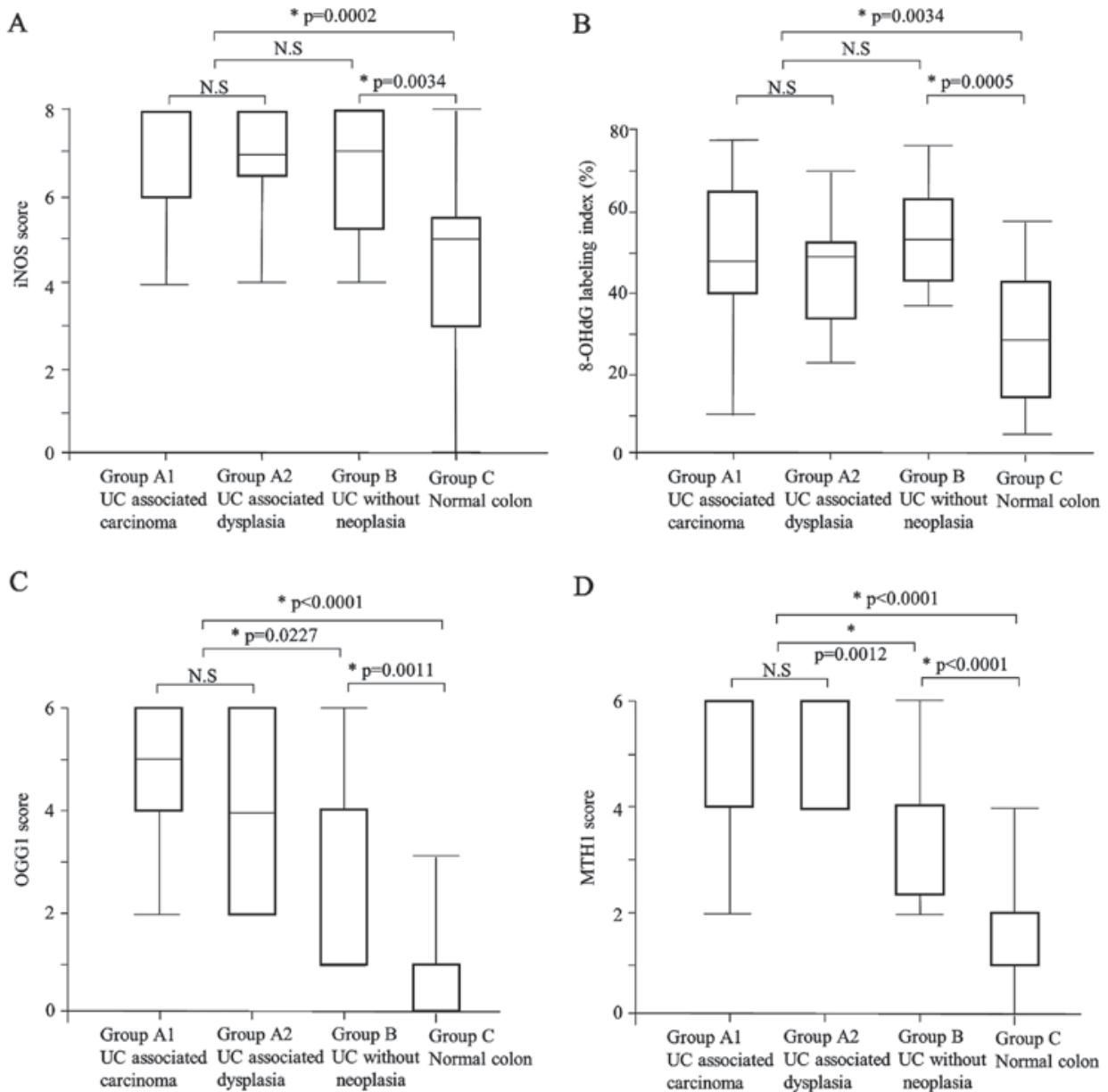

Figure 2. The expression levels of (A) iNOS, (B) 8-OHdG, (C) OGG1 and (D) MTH1 in the UC-associated carcinomas (Group A1) and dysplasias (Group A2), the UC cases without neoplasm (Group B) and the normal colon (Group C). (A-D) Group A (i.e., the combined Group A1 and Group A2) and Group B showed a significantly higher expression of each molecule compared to the Group C. (C and D) In addition, Group A showed significantly higher expressions of OGG1 and MTH1 compared to the than Group B. (A-D) There was no difference between Group A1 and A2 in terms of the expression of these molecules. 


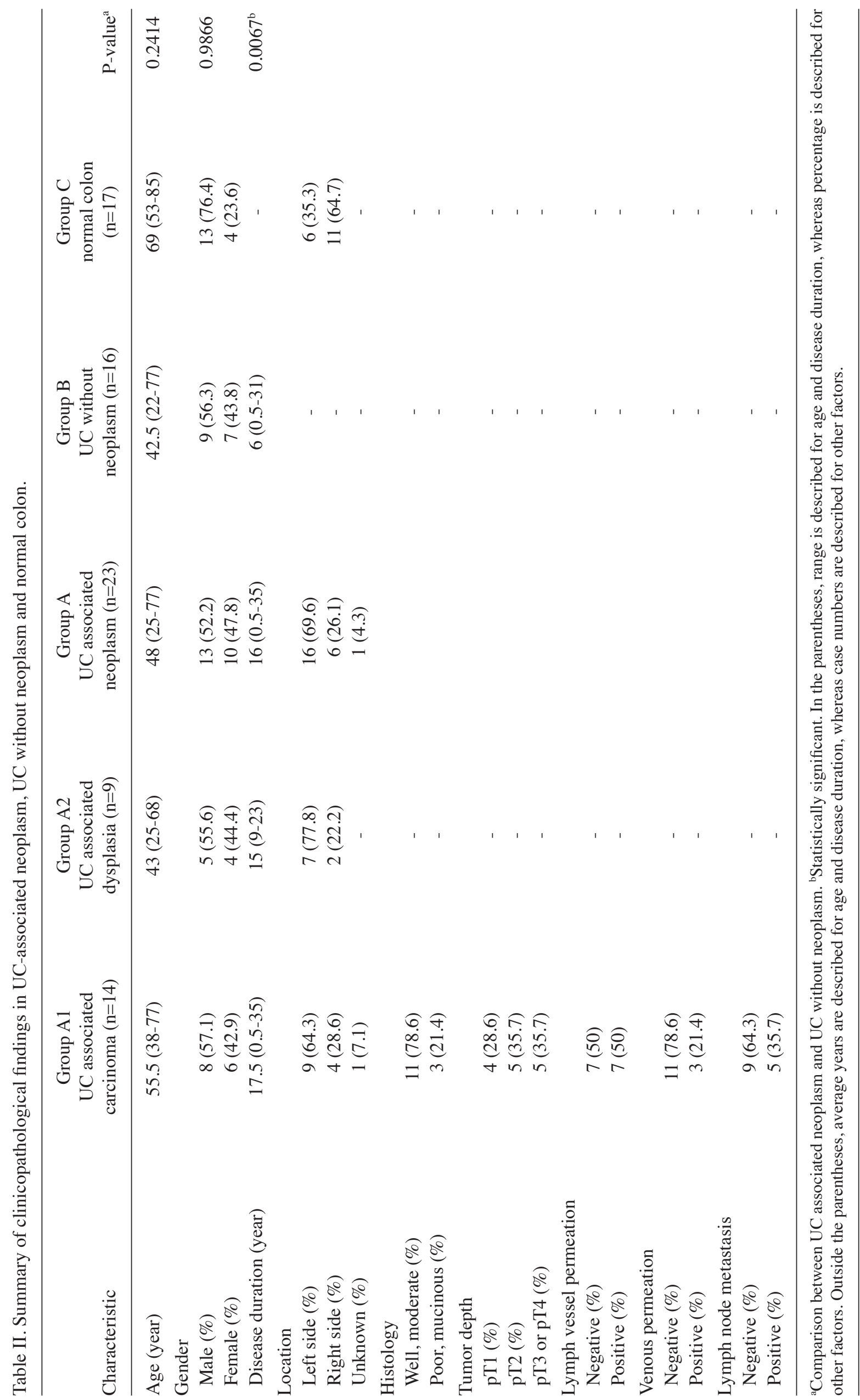




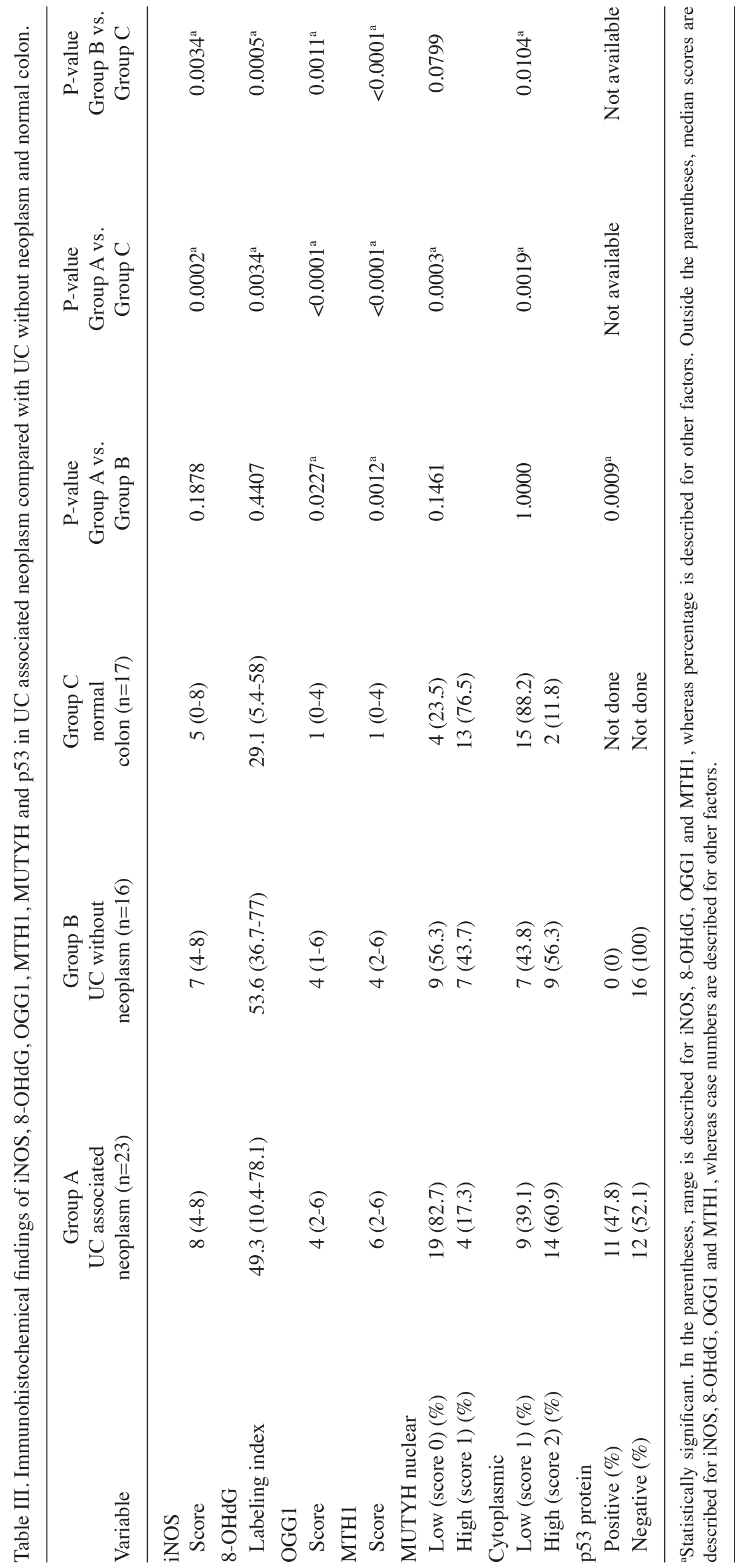


Table IV. Immunohistochemical findings of iNOS, 8-OHdG, OGG1, MTH1, MUTYH and p53 and TP53 mutation in UC associated carcinoma compared with UC associated dysplasia.

\begin{tabular}{|c|c|c|c|}
\hline Variable & Group A1UC associated carcinoma $(n=14)$ & Group A2 UC associated dysplasia $(\mathrm{n}=9)$ & P-value \\
\hline \multicolumn{4}{|l|}{ iNOS } \\
\hline Score & $8(4-8)$ & $7(4-8)$ & 0.7007 \\
\hline \multicolumn{4}{|l|}{ 8-OHdG } \\
\hline Labeling index & $49.2(10.4-78.1)$ & $49.3(23.4-69.1)$ & 0.6821 \\
\hline \multicolumn{4}{|l|}{ OGG1 } \\
\hline Score & $5(2-6)$ & $4(2-6)$ & 0.5623 \\
\hline \multicolumn{4}{|l|}{ MTH1 } \\
\hline Score & $6(2-6)$ & $4(4-6)$ & 0.7209 \\
\hline \multicolumn{4}{|l|}{ MUTYH nuclear } \\
\hline Low (score 0$)(\%)$ & $11(78.6)$ & $8(88.9)$ & 0.5241 \\
\hline High (score 1) $(\%)$ & $3(21.4)$ & $1(11.1)$ & \\
\hline \multicolumn{4}{|l|}{ Cytoplasmic } \\
\hline Low (score 1) $(\%)$ & $2(14.3)$ & $7(77.8)$ & $0.0023^{\mathrm{a}}$ \\
\hline High (score 2) $(\%)$ & $12(85.7)$ & $2(22.2)$ & \\
\hline \multicolumn{4}{|l|}{ p53 protein } \\
\hline Positive (\%) & $4(28.6)$ & $7(77.8)$ & $0.0211^{\mathrm{a}}$ \\
\hline Negative (\%) & $10(71.4)$ & $2(22.2)$ & \\
\hline \multicolumn{4}{|l|}{ TP53 mutation ${ }^{\mathrm{b}}$} \\
\hline Positive (\%) & $5(35.7)$ & $5(62.5)$ & 0.2248 \\
\hline Negative (\%) & $9(64.3)$ & $3(37.5)$ & \\
\hline
\end{tabular}

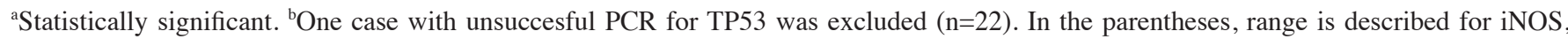
8-OHdG, OGG1 and MTH1, whereas percentage is described for other factors. Outside the parentheses, median scores are described for iNOS, 8-OHdG, OGG1 and MTH1, whereas case numbers are described for other factors.

cytoplasmic expression were different in each case. The OGG1 expression score was significantly higher in Group A (median: 4) compared to Group B (median: 4) and Group C (median: 1) $(P=0.0227, P<0.0001$, respectively) (Table III; Figs. 1E and 2C). The OGG1 expression score was also significantly higher in Group B than in Group C ( $\mathrm{P}=0.0011)$. There was no significant difference in OGG1 expression between Group A1 and Group A2 (Table IV).

MTH1. The MTH1 expression score was significantly higher in Group A (median: 6) compared to Group B (median: 4) and Group $\mathrm{C}$ (median: 1) $(\mathrm{P}=0.0012, \mathrm{P}<0.0001$, respectively) (Table III; Figs. 1F and 2D). The MTH1 expression was also significantly higher in Group B compared to Group C $(\mathrm{P}<0.0001)$. There was no significant difference in MTH1 expression between Group A1 and Group A2 (Table IV).

MUTYH. Regarding the nuclear expression of MUTYH, each case was scored as 0 or 1; no cases were judged as score 2 . The nuclear expression of MUTYH was positive (score 1) in 4/23 cases (17.3\%) in Group A, 7/16 cases (43.7\%) in Group B and 13/17 cases (76.5\%) in Group C (Table III and Fig. 1G). Group $\mathrm{A}$ and Group B showed significantly lower nuclear expression of MUTYH compared to the Group C $(\mathrm{P}=0.0003$ and $\mathrm{P}=0.0799$, respectively). There was no significant difference in MUTYH nuclear expression between Group A1 and Group A2 (Table IV).
As for the cytoplasmic expression of MUTYH, each case was scored 1 or 2 ; no cases were judged as score 0 . High (score 2) cytoplasmic expression of MUTYH was present in $14 / 23$ cases (60.9\%) in Group A, 9/16 cases (56.3\%) in Group $\mathrm{B}$ and $2 / 17$ cases $(11.8 \%)$ in Group C (Table III and Fig. 1G). Thus, Group A and Group B showed significantly higher cytoplasmic expression of MUTYH compared to the Group C ( $\mathrm{P}=0.019, \mathrm{P}=0.0104$, respectively). Notably, Group A1 showed significantly higher cytoplasmic expression of MUTYH compared to Group A2 ( $\mathrm{P}=0.0023)$ (Table IV).

p53. A nuclear accumulation of p53 protein was present in $11 / 23$ cases (47.8\%) of Group A, but it was not observed in Group $\mathrm{B}(0 / 16$ cases $)(\mathrm{P}=0.0009)$ (Table III and Fig. $1 \mathrm{H})$. In addition, Group A2 showed a significantly higher frequency of p53 accumulation compared to the Group A1 ( $\mathrm{P}=0.0211)$ (Table IV).

In Group A2, 7/9 cases (77.8\%) showed nuclear accumulation of p53 protein, and 5/8 cases $(62.5 \%)$ showed TP53 mutation. Four of the five dysplasias (i.e., Group A2) with TP53 mutation revealed nuclear accumulation of p53 protein (4/5 cases, $80 \%$ ). In Group A1, , 4/14 cases (28.6\%) showed nuclear accumulation of p53 protein, and 5/14 cases $(35.7 \%)$ showed TP53 mutation in Group A1. Of the five carcinomas (i.e., Group A1) with TP53 mutation, only one case revealed nuclear accumulation of p53 protein (1/5 cases, 20\%). The concordance rate between nuclear accumulation of p53 protein and TP53 mutation was 
Table V. The correlations between 8-OHdG accumulation and immunohistochemical features of UC associated neoplasm ( $\mathrm{n}=22)^{\mathrm{a}}$.

8-OHdG accumulation

\begin{tabular}{|c|c|c|c|}
\hline Immunohistochemistry & $\operatorname{High}(\mathrm{n}=11)$ & Low $(n=11)$ & P-value \\
\hline Age (year) & $49(26-77)$ & $44(25-68)$ & 0.5759 \\
\hline \multicolumn{4}{|l|}{ Gender } \\
\hline Male $(\%)$ & $5(45.5)$ & $8(72.7)$ & \multirow[t]{2}{*}{0.3870} \\
\hline Female $(\%)$ & $6(54.5)$ & $3(27.3)$ & \\
\hline Disease duration (year) & $17(9-35)$ & $12(0.5-24)$ & 0.3832 \\
\hline \multicolumn{4}{|l|}{ iNOS } \\
\hline Score & $7(4-8)$ & $8(5-8)$ & 0.0819 \\
\hline \multicolumn{4}{|l|}{ OGG1 } \\
\hline Score & $4(2-6)$ & $4(2-6)$ & 0.5482 \\
\hline \multicolumn{4}{|l|}{ MTH1 } \\
\hline Score & $4(4-6)$ & $6(2-6)$ & 0.9714 \\
\hline \multicolumn{4}{|l|}{ MUTYH nuclear } \\
\hline Low (score 0) $(\%)$ & $8(72.7)$ & $10(90.9)$ & \multirow[t]{2}{*}{0.5865} \\
\hline High (score 1) $(\%)$ & $3(27.3)$ & $1(9.1)$ & \\
\hline \multicolumn{4}{|l|}{ Cytoplasmic } \\
\hline Low (score 1) (\%) & $3(27.3)$ & $5(45.5)$ & \multirow[t]{2}{*}{0.6594} \\
\hline High (score 2) (\%) & $8(72.7)$ & $6(54.5)$ & \\
\hline \multicolumn{4}{|l|}{ p53 protein } \\
\hline Positive (\%) & $6(54.5)$ & $4(36.4)$ & \multirow[t]{2}{*}{0.3918} \\
\hline Negative (\%) & $5(45.5)$ & $7(63.6)$ & \\
\hline \multicolumn{4}{|l|}{ TP53 mutation } \\
\hline Positive (\%) & $4(36.4)$ & $6(54.6)$ & \multirow[t]{2}{*}{0.6699} \\
\hline Negative (\%) & $7(63.6)$ & $5(45.4)$ & \\
\hline
\end{tabular}

aOne case with unsuccessful PCR for TP53 was excluded. In the parentheses, range is described for iNOS, OGG1 and MTH1, whereas percentage is described for other factors. Outside the parentheses, median scores are described for iNOS, OGG1 and MTH1, whereas case numbers are described for other factors.

not significantly different between the two groups, but in the dysplasias (Group A 2), this rate tended to be higher than that in the carcinomas (Group A1) $(\mathrm{P}=0.058)$.

\section{Mutational analysis}

TP53. The results of our mutation analysis as well as the clinicopathological data of Group Athe UC+ group are summarized in Table VI. The PCR for TP53 was successful in 22 cases of Group A. The TP53 mutation was present in a total of 10 of the $22(45.5 \%)$ cases, including 5/14 cases (35.7\%) of Group A1 and $5 / 8$ cases $(62.5 \%)$ of Group A2. There was no significant difference in the frequency of TP53 mutation between these two groups. Among the 10 cases with TP53 mutation, transversion and transition mutations were present in two and eight cases, respectively.

We then checked the correlation between TP53 mutation and inflammation-associated marker expressions; no significant correlation was observed (Table VII).

$K$-ras. The mutation analysis of $K$-ras was successful in 21 cases in Group A. We found that 2 of 21 (9.5\%) cases had
$K$-ras gene mutation at codon 12 ; one mutation was the transversion type and the other was the transition type (Table VI).

IDH1. No cases in Group A had IDH1 gene mutation.

\section{Discussion}

Our present findings demonstrated that the expression levels of iNOS, 8-OHdG, OGG1 and MTH1 were significantly higher in UCAN and UC samples than in non-inflamed mucosa. In addition, the OGG1 and MTH1 expressions were significantly higher in the UCAN than in the UC cases. It has been reported that increased levels of $8-\mathrm{OHdG}$ induce the activation of MTH1 or OGG1 to minimize 8-OHdG accumulation in mammalian DNA $(13,30)$. Similarly in UC, oxidative stress may upregulate defense systems such as MTH1 and OGG1 to minimize 8-OHdG accumulation.

Liao et al reported that OGG1 knockout mice showed a significantly increased risk of adenocarcinoma development in the colon compared to wild-type mice after the induction of dextran sulfate sodium-induced colitis (31). In breast 


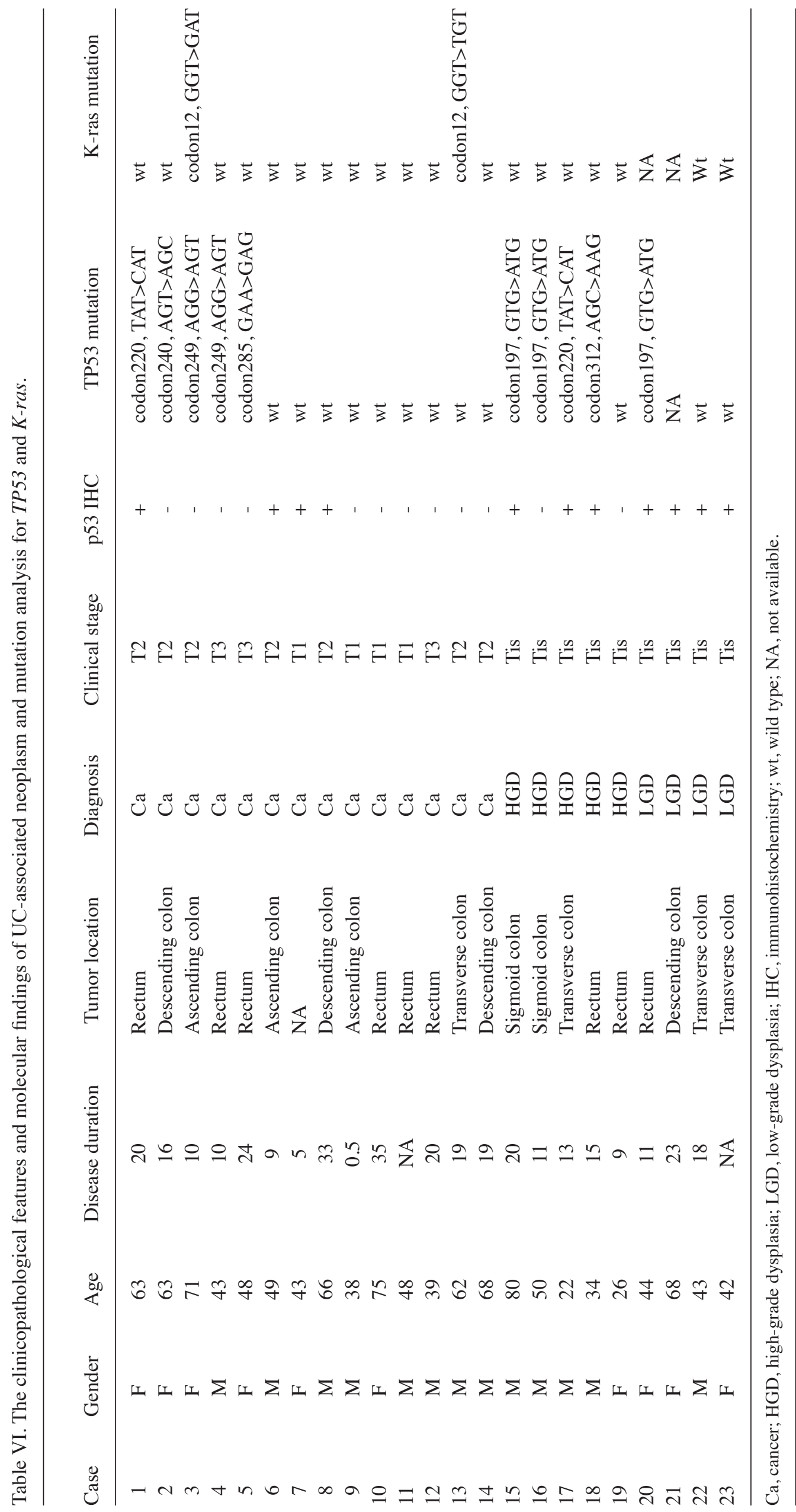


Table VII. The correlations between TP53 mutational status and clinicopathological factors or immunohistochemical features of UC-associated neoplasia $(n=22)^{\mathrm{a}}$.

TP53 mutation

\begin{tabular}{|c|c|c|c|}
\hline \multirow[b]{2}{*}{ Variable } & & \multirow[b]{2}{*}{ P-value } \\
\hline & Positive $(\%)(\mathrm{n}=10)$ & Negative $(\%)(\mathrm{n}=12)$ & \\
\hline Age (year) & $46(25-71)$ & $45.5(26-77)$ & 0.8948 \\
\hline \multicolumn{4}{|l|}{ Gender } \\
\hline Male (\%) & $5(50)$ & $8(66.6)$ & \multirow[t]{2}{*}{0.4285} \\
\hline Female $(\%)$ & $5(50)$ & $4(33.3)$ & \\
\hline Disease duration (year) & $14(10-24)$ & $18.5(0.5-35)$ & 0.9698 \\
\hline \multicolumn{4}{|l|}{ iNOS } \\
\hline Score & $8(6-8)$ & $7(4-8)$ & 0.1099 \\
\hline \multicolumn{4}{|l|}{ 8-OHdG } \\
\hline Labelling index (\%) & $45.9(23.4-78.1)$ & $50.7(10.4-69.1)$ & 0.9212 \\
\hline \multicolumn{4}{|l|}{ OGG1 } \\
\hline Score & $4(2-6)$ & $6(2-6)$ & 0.1028 \\
\hline \multicolumn{4}{|l|}{ MTH1 } \\
\hline Score & $6(4-6)$ & $4(2-6)$ & 0.3515 \\
\hline \multicolumn{4}{|l|}{ MUTYH nuclear } \\
\hline Low (score 0) $(\%)$ & $8(80)$ & $10(83.3)$ & \multirow[t]{2}{*}{0.8403} \\
\hline High (score 1) (\%) & $2(20)$ & $2(16.7)$ & \\
\hline \multicolumn{4}{|l|}{ Cytoplasmic } \\
\hline Low (score 1) $(\%)$ & $3(30)$ & $5(41.7)$ & \multirow[t]{2}{*}{0.5711} \\
\hline High (score 2) (\%) & $7(70)$ & $7(58.3)$ & \\
\hline \multicolumn{4}{|l|}{ p53 protein } \\
\hline Positive (\%) & $5(50)$ & $5(41.7)$ & \multirow[t]{2}{*}{0.6959} \\
\hline Negative $(\%)$ & $5(50)$ & $7(58.3)$ & \\
\hline
\end{tabular}

${ }^{a}$ One case with unsuccessful PCR for TP53 was excluded. In the parentheses, range is described for age, disease duration, iNOS, 8-OHdG, OGG1 and MTH1, whereas percentage is described for other factors. Outside the parentheses, average years are described for age and disease duration, whereas case numbers are described for other factors.

cancer, reduced OGG1 expression was correlated with poor prognosis (17). On the other hand, Kubo et al showed 8-OHdG accumulation and cytoplasmic OGG1 overexpression in esophageal squamous cell carcinoma (16), They also showed that cytoplasmic OGG1 expression was correlated with the depth of cancer, lymph node metastasis and the stage of progression. In the present study, the OGG1 cytoplasmic expression was higher in UCAN than UC cases.

It is reported that OGG1 protein is present in the nucleus and mitochondria and that the protein at both of these sites work as DNA repair protein. The dysfunction of each OGG1 leads to high 8-OHdG accumulation and cell death (32). These findings suggested that OGG1 overexpression might represent persisting oxidative stress and cellular response in UCAN and unlike in mouse models, the upregulation of OGG1 function may play some role in the pathogenesis of human UCAN.

Tsuzuki et al showed that in an MTH-1-deficient mouse model, a greater number of tumors were formed in the lung, liver, and stomach compared to MTH1 wild-type mice (33). In contrast, Song et al showed that MTH1 expression was significantly higher in human gastric cancer tissue than para-cancer tissue, and that MTH1 expression correlated with $8-\mathrm{OHdG}$ accumulation (34). These findings may be explained in part by the notion that cancer cells may require MTH1 to avoid both DNA damage and cell death because an excessive accumulation of $8-\mathrm{OHdG}$ leads to tumor cell death $(35,36)$. In the present study, the MTH1 expression was higher in UCAN than in the UC and non-inflamed mucosa. Our results may support the hypothesis that MTH1 is required for cancer survival for defense against oxidative damage in UCAN. Similar to the previous study, the present UCAN and UC cases exhibited higher cytoplasmic expression and lower nuclear expression of MUTYH compared to the non-inflamed mucosa. Such an abnormal expression pattern of MUTYH may represent dysfunction of MUTYH, as we had suggested (18).

In general, 8-OHdG accumulation leads to the $\mathrm{G}: \mathrm{C}$ to $\mathrm{T}$ :A and $\mathrm{A}: \mathrm{T}$ to $\mathrm{C}: \mathrm{G}$ transversion mutations (10). Chaubert et al reported that $K$-ras mutations were present in $44 \%$ of UCAN patients with a predominance of G:C to T:A transversion (37). However, in our series, despite the accumulation of $8-\mathrm{OHdG}$, transversion mutations of $K$-ras or TP53 gene were not frequent. 
For example, among our 21 cases of UCAN, K-ras mutation was identified in two (9.5\%) cases, one of whom showed a G:C to T:A transversion mutation. Although we detected the TP53 mutations in $10 / 22$ cases $(45.5 \%)$ of UCAN, only two cases showed transversion mutations.

The frequency of TP53 mutation was higher in our dysplasia cases compared to the carcinoma cases. Carcinoma may arise from other factors, such as genetic alterations in tumor suppressor genes, oncogenes and genes encoding DNA repair proteins, as well as from loss of genomic stability.

We also observed that the expression levels of OGG1, MUTYH and MTH1 were not correlated with the presence of TP53 gene mutation or p53 protein accumulation. It thus seems to be less likely that a dysfunction of OGG1, MUTYH or MTH1 caused the excessive accumulation of 8-OHdG and the subsequent transversion mutation of K-ras or TP53 in UCAN. However, the possibility remains that an accumulation of 8-OHdG might cause a transversion mutation of other genes that would participate in the pathogenesis of UCAN. As an additional possibility, dysfunction of OGG1 and MUTYH caused by TP53 mutation might play a role in the tumorigenesis in some populations of UCAN. It has been reported that, since OGG1 and MUTYH are transcriptionally regulated by p53, p53 deficiency leads to OGG1 and MUTYH dysfunction, resulting in escape from programmed cell death under oxidative stress and the promotion of tumorigenesis $(38,39)$. However, further study is necessary to elucidate the mechanism of TP53 mutation and its role in the tumorigenesis of UCAN.

A previous study revealed that isocitrate dehydrogenase 1(IDH1) mutations were present in $1 \%$ of sporadic colorectal carcinomas (22). Hartman et al also reported that adenocarcinomas associated with inflammatory bowel disease more frequently demonstrated IDH1 mutations than conventional intestinal adenocarcinomas did (13\% vs. $0 \%)$ (23). In addition, IDH1 mutations were more frequently observed in Crohn's disease-associated neoplasms than UC-associated neoplasms in their study. In the present study, no IDH1 gene mutation was detected in the neoplasms associated with UC. These findings suggest that IDH1 mutation may be exceptional in UCAN.

In conclusion, the results of our study demonstrated that iNOS, 8-OHdG, MTH1 and OGG1 were accumulated in UCAN and the inflamed mucosa of UC patients. We also observed that the expressions of MTH1 and OGG1 were higher in UCAN than in UC. Our results suggest that both inflamed mucosa and neoplasms of UC are exposed to persisting oxidative damage, which may lead to the increased expressions of MTH1 and OGG1, and possibly to UC-related carcinogenesis.

\section{Acknowledgements}

The authors would like to thank the Research Support Center, Graduate School of Medical Sciences, Kyushu University for their technical support.

\section{References}

1. Jess T, Rungoe C and Peyrin-Biroulet L: Risk of colorectal cancer in patients with ulcerative colitis: A meta-analysis of population-based cohort studies. Clin Gastroenterol Hepatol 10: 639-645, 2012
2. Jess T, LoftusEV Jr, Velayos FS, Harmsen WS, Zinsmeister AR, Smyrk TC, Tremaine WJ, MeltonLJ III, Munkholm P and Sandborn WJ: Incidence and prognosis of colorectal dysplasia in inflammatory bowel disease: A population-based study from Olmsted County, Minnesota. Inflamm Bowel Dis 12: 669-676, 2006.

3. Brentnall TA, Haggitt RC, Rabinovitch PS, Kimmey MB, Bronner MP, Levine DS, Kowdley KV, Stevens AC, Crispin DA, Emond $\mathrm{M}$ and Rubin CE: Risk and natural histoy of colonic neoplasia in patients with primary sclerosing cholangitis and ulcerative colitis. Gastroenterology 110: 331-338, 1996.

4. Nuako KW, Ahlquist DA, Mahoney DW, Schaid DJ, Siems DM and Lindor NM: Familial predisposition for colorectal cancer in chronic ulcerative colitis: A case-control study. Gastroenterology 115: 1079-1083, 1998.

5. Devroede GJ, Taylor WF, Sauer WG, Jackman RJ and Stickler GB: Cancer risk and life expectancy of children with ulcerative colitis. N Engl J Med 285: 17-21, 1971.

6. D'Incà R, Cardin R, Benazzato L, Angriman I, Martines D and Sturniolo GC: Oxidative DNA damage in the mucosa of ulcerative colitis increases with disease duration and dysplasia. Inflamm Bowel Dis 10: 23-27, 2004.

7. Kojima M, Morisaki T, Tsukahara Y, Uchiyama A, Matsunari Y, Mibu R and Tanaka M: Nitric oxide synthase expression and nitric oxide production in human colon carcinoma tissue. J Surg Oncol 70: 222-229, 1999.

8. Choudhari SK, Chaudhary M, Bagde S, Gadbail AR and Joshi V: Nitric oxide and cancer: A review. World J Surg Oncol 11: 118, 2013.

9. Vannini F, Kashfi K and Nath N: The dual role of iNOS in cancer. Redox Biol 6: 334-343, 2015.

10. Nakabeppu Y, Tsuchimoto D, Ichinoe A, Ohno M, Ide Y, Hirano S, Yoshimura D, Tominaga Y, Furuichi M and Sakumi K: Biological significance of the defense mechanisms against oxidative damage in nucleic acids caused by reactive oxygen species: From mitochondria to nuclei. Ann N Y Acad Sci 1011: 101-111, 2004.

11. Shibutani S, Takeshita M and Grollman AP: Insertion of specific bases during DNA synthesis past the oxidation-damaged base 8-oxodG. Nature 349: 431-434, 1991.

12. Vakakanidis A, Vlachogianni T and Fiotakis C: 8-hydroxy-2'-deoxyguanosine (8-OHdG): A critical biomarker of oxidative stress and carcinogenesis. J Environ Sci Health C Environ Carcinog Ecotoxicol Rev 27: 120-139, 2009.

13. Kondo S, Toyokuni S, Tanaka T, Hiai H, Onodera H, Kasai H and Imamura M: Overexpression of the hOGG1 gene and high 8-hydroxy-2'-deoxyguanosine (8-OHdG) lyase activity in human colorectal carcinoma: Regulation mechanism of the 8-OHdG level in DNA. Clin Cancer Res 6: 1394-1400, 2000.

14. Sekiguchi $M$ and Tsuzuki T: Oxidative nucleotide damage: Consequences and prevention. Oncogene 21: 8895-8904, 2002.

15. García-Quispes WA, Pérez-Machado G, Akdi A, Pastor S, Galofré P, Biarnés F, Castell J, Velázquez A and Marcos R: Association studies of OGG1, XRCC1, XRCC2 and XRCC3 polymorphisms with differentiated thyroid cancer. Mutat Res 709-710: 67-72, 2011.

16. Kubo N, Morita M, Nakashima Y, Kitao H, Egashira A, Saeki H, Oki E, Kakeji Y, Oda Y and Maehara Y: Oxidative DNA damage in human esophageal cancer: Clinicopathological analysis of 8-hydroxydeoxyguanosine and its repair enzyme. Dis Esophagus 27: 285-293, 2014.

17. Karihtala P, Kauppila S, Puistola U and Jukkola-Vuorinen A: Absence of the DNA repair enzyme human 8-oxoguanine glycosylase is associated with an aggressive breast cancer phenotype. $\mathrm{Br}$ J Cancer 106: 344-347, 2012.

18. Gushima M, Hirahashi M, Matsumoto T, Fujita K, Fujisawa R, Mizumoto K, Nakabeppu Y, Iida M, Yao T and Tsuneyoshi M: Altered expression of MUTYH and an increase in 8-hydroxydeoxyguanosine are early events in ulcerative colitis-associated carcinogenesis. J Pathol 219: 77-86, 2009.

19. Grasso F, Di Meo S, De Luca G, Pasquini L, Rossi S, Boirivant M, Biffoni M, Bignami M and Di Carlo E: The MUTYH base excision repair gene protects against inflammation-associated colorectal carcinogenesis. Oncotarget 6: 19671-19684, 2015.

20. Scarpa M, Castagliuolo I, Castoro C, Pozza A, Scarpa M, Kotsafti A and Angriman I: Inflammatory colonic carcinogenesis: A review on pathogenesis and immunosurveillance mechanisms in ulcerative colitis. World J Gastroenterol 20: 6774-6785, 2014. 
21. Yin J, Harpaz N, Tong Y, Huang Y, Laurin J, Greenwald BD, Hontanosas M, Newkirk C and Meltzer SJ: p53 point mutations in dysplastic and cancerous ulcerative colitis lesions. Gastroenterology 104: 1633-1639, 1993.

22. Borger DR, Tanabe KK, Fan KC, Lopez HU, Fantin VR, Straley KS, Schenkein DP, Hezel AF, Ancukiewicz M Liebman HM, et al: Frequent mutation of isocitrate dehydrogenase (IDH) 1 and IDH2 in cholangiocarcinoma identified through broad-based tumor genotyping. Oncologist 17: 72-79, 2012.

23. Hartman DJ, Binion D, Regueiro M, Schraut W, Bahary N, Sun W, Nikiforova M and Pai RK: Isocitrate dehydrogenase-1 is mutated in inflammatory bowel disease-associated intestinal adenocarcinoma with low-grade tubuloglandular histology but not in sporadic intestinal adenocarcinoma. Am J Surg Pathol 38 1147-1156, 2014.

24. Riddell RH, Goldman H, Ransohoff DF, Appelman HD, Fenoglio CM, Haggitt RC, Ahren C, Correa P, Hamilton SR, Morson BC, et al: Dysplasia in inflammatory bowel disease: Standardized classification with provisional clinical applications Human Pathol 11: 931-968, 1983.

25. Brennan PA, Palacios-Callender M, Zaki GA, Spedding AV and Langdon JD: Type II nitric oxide synthase (NOS2) expression correlates with lymph node status in oral squamous cell carcinoma. J Oral Pathol Med 30: 129-134, 2001.

26. Maehara Y, Tomoda M, Hasuda S, Kabashima A, Tokunaga E, Kakeji Y and Sugimachi K: Prognostic value of $\mathrm{p} 53$ protein expression for patients with gastric cancer-a multivariate analysis. Br J Cancer 79: 1255-1261, 1999.

27. Feng CW, Wang LD, Jiao LH, Liu B, Zheng S and Xie XJ: Expression of p53, inducible nitric oxide synthase and vascular endothelial growth factor in gastric precancerous and cancerous lesions: Correlation with clinical features. BMC Cancer 2: 8, 2002.

28. Oda Y, Sakamoto A, Satio T, Kawauchi S, Iwamoto Y and Tsuneyoshi M: Molecular abnormalities of p53, MDM2 and H-ras in synovial sarcoma. Mod Pathol 13: 994-1004, 2000.

29. Fujita K, Yamamoto H, Matsumoto T, Hirahashi M, Gushima M, Kishimoto J, Nishiyama K, Taguchi T, Yao T and Oda Y: Sessile serrated adenoma with early neoplastic progression: A clinicopathologic and molecular study. Am J Surg Pathol 35: 295-304, 2011.
30. Kajitani K, Yamaguchi H, Dan Y, Furuichi M, Kang D and Nakabeppu Y: MTH1, an oxidized purine nucleoside triphosphatase, suppresses the accumulation of oxidative damage of nucleic acids in the hippocampal microglia during kainate-induced excitotoxicity. J Neurosci 26: 1688-1698, 2006.

31. Liao J, Seril DN, Lu GG, Zhang M, Toyokuni S, Yang AL and Yang GY: Increased susceptibility of chronic ulcerative colitis-induced carcinoma development in DNA repair enzyme Ogg1 deficient mice. Mol Carcinog 47: 638-646, 2008.

32. Nakabeppu Y: Cellular levels of 8-oxoguanine in either DNA or the nucleotide pool play pivotal roles in carcinogenesis and survival of cancer cells. Int J Mol Sci 15: 12543-12557, 2014.

33. Tsuzuki T, Egashira A, Igarashi H, Iwakuma T, Nakatsuru Y, Tominaga Y, Kawate H, Nakao K, Nakamura K, Ide F, et al: Spontaneous tumorigenesis in mice defective in the MTH1 gene encoding 8-oxo-dGTPase. Proc Natl Acad Sci USA 98: 11456-11461, 2001.

34. Song WJ, Jiang P, Cai JP and Zheng ZQ: Expression of cytoplasmic 8-oxo-Gsn and MTH1 correlates with pathological grading in human gastric cancer. Asian Pac J Cancer Prev 16: 6335-6338, 2015.

35. Gad H, Koolmeister T, Jemth AS, Eshtad S, Jacques SA, Ström CE, Svensson LM, Schultz N, Lundbäck T, Einarsdottir BO, et al: MTH1 inhibition eradicates cancer by preventing sanitation of the dNTP pool. Nature 508, 215-221, 2014.

36. Huber KV, Salah E, Radic B, Gridling M, Elkins JM, Stukalov A, Jemth AS, Göktürk C, Sanjiv K, Strömberg K, et al: Stereospecific targeting of MTH1 by (S)-crizotinib as an anticancer strategy. Nature 508: 222-227, 2014

37. Chaubert P, Benhattar J, Saraga E and Costa J: K-ras mutations and p53 alterations in neoplastic and nonneoplastic lesions associated with longstanding ulcerative colitis. Am J Pathol 144: 767-775, 1994.

38. Oka S, Leon J, Tsuchimoto D, Sakumi K and Nakabeppu Y: MUTYH, an adenine DNA glycosylase, mediates p53 tumor suppression via PARP-dependent cell death. Oncogenesis 4: e142, 2015 .

39. Chatterjee A. Mambo E, Osada M, Upadhyay S and Sidransky D: The effect of p53-RNAi and p53 knockout on human 8-oxoguanine DNA glycosylase (hOgg1) activity. FASEB J 20: 112-114, 2006. 